\title{
TEORIA ESTRUTURAL-FUNCIONALISTA DA CRIMINALIDADE E FUNCIONALISMO JURÍDICO- PENAL: A INFLUÊNCIA DE DURKHEIM NA DOGMÁTICA PENAL CONTEMPORÂNEA
}

STRUCTURAL-FUNCTIONAL THEORY OF CRIMINALITY AND LEGAL-CRIMINAL FUNCTIONALISM: DURKHEIM'S INFLUENCE ON CONTEMPORARY CRIMINAL DOGMATICS

Ricardo Freitas ${ }^{1}$ FADIC - PE

\section{Resumo}

Partindo do pressuposto de que o penalismo ainda ignora em considerável medida a importância da contribuição teórica de Durkheim para a dogmática do Direito Penal, pretende-se examinar a influência exercida pela teoria estrutural-funcionalista da criminalidade na dogmática jurídico-penal funcionalista mediante a exposição crítica de seus principais aspectos.

Palavras-chave

Teoria estrutural-funcionalista da criminalidade. Funcionalismo. Teoria teleológicofuncional. Teoria funcionalista sistêmica. Crime. Pena.

\section{Abstract}

Based on the assumption that penalism still ignores to a considerable extent the importance of Durkheim's theoretical contribution to the dogmatics of Criminal Law, it is intended to examine the influence exerted by the structural-functionalist theory of criminality on functionalist legal-penal dogmatics through critical exposure of its main aspects.

Keywords

${ }^{1}$ Professor de Direito Penal do Programa de Pós-graduação em Direito da Faculdade Damas da Instrução Cristã e da Faculdade de Direito do Recife (UFPE). 
Structural-functionalist theory of criminality. Functionalism. Teleologicalfunctional theory. Systemic functionalist theory. Crime. Penalty.

\section{Introdução: teoria estrutural-funcionalista e dogmática do Direito Penal.}

Enquanto corrente da sociologia geral, o funcionalismo pretende, sobretudo, investigar e descrever o surgimento das instituições sociais e sua contribuição específica para a estabilização da sociedade. Consequentemente, o funcionalismo demostra interesse nas instituições jurídico-penais por acreditar que elas têm considerável importância para a conservação e reprodução da estrutura social, bem como para a compreensão das ações humanas.

No âmbito da sociologia criminal, as teorias funcionalistas da criminalidade assumem que a estrutura e o funcionamento do sistema penal e de suas instituições devem ser investigados em conexão com a totalidade do sistema social. Além disso, de acordo com as teorias funcionalistas da criminalidade, o sistema penal como um todo tem como função básica a própria manutenção e reprodução do sistema social.

Muito embora o funcionalismo tenha sido a orientação teórica dominante na sociologia e na antropologia na primeira metade do século $\mathrm{XX}$, no mencionado período sua influência sobre a denominada ciência do direito penal foi nula ou praticamente nula, comprovando, dessa maneira, a inexistência de comunicação 
interdisciplinar plenamente satisfatória entre a dogmática do direito penal e a criminologia sociológica. Somente nas derradeiras décadas do século anterior é que a dogmática penal inclinou-se decididamente na direção da sociologia, tendo sofrido influência da orientação funcionalista que, com o passar do tempo, tende aparentemente a tornar-se hegemônica no âmbito da dogmática do Direito Penal.

Em geral, a doutrina reconhece a influência exercida por Parsons e, sobretudo, por Luhmann, sobre os dogmáticos funcionalistas, porém raramente se refere à decisiva contribuição proporcionada pela teoria estrutural-funcionalista de Durkheim ao Direito Penal contemporâneo. Quando o faz, o que é infrequente, a doutrina penal não se digna a analisar e dimensionar esta contribuição, limitando-se a admitir de maneira sucinta sua importância. Por isso, ambicionando preencher esta lacuna, mas sem ter a pretensão de analisar os diversos enfoques funcionalistas, missão que já foi cumprida satisfatoriamente por estudiosos de todos os quadrantes, esta reflexão limita-se exclusivamente a verificar em que medida a teoria estruturalfuncionalista da criminalidade exerce influência sobre $o$ funcionalismo penal. Para tanto, o texto parte de prévia exposição e análise crítica das ideias de Durkheim sobre o crime e a pena. Secundariamente, esta investigação pretende esmiuçar os principais aspectos da teoria estrutural-funcionalista da criminalidade com o objetivo da apresentar ao leitor, em particular, quais as contribuições que ela nos oferece para a compreensão acerca do fenômeno social da criminalidade, do crime e da pena.

2. Teoria estrutural-funcionalista da anomia: a função do crime e da pena. 
Durkheim é um dos maiores nomes da sociologia de todos os tempos. A sua sociologia criminal é marcadamente determinista, não obstante, Durkheim confere um papel pouco relevante às causas e motivações individuais do delito (FIGUEIREDO DIAS; COSTA ANDRADE, 1997, p.314). Para ele, a explicação da criminalidade, assim como das condutas desviadas em geral, é extraída da dinâmica da sociedade e não do comportamento individual. Portanto, sua sociologia opõe-se tanto aos filósofos e penalistas clássicos contratualistas que conceberam o crime como produto de uma decisão livre e racional como aos adeptos do positivismo naturalista (VOLD; BERNARD; SNIPES, 2002, p.100). Contra o positivismo naturalista, Durkheim (2012, p.82), inclusive, sustenta a opinião de que o crime não tem caráter patológico, mas é um fenômeno social e como tal deve ser estudado. Esta seção pretende expor as bases da teoria estruturalfuncionalista e, na sequência, a concepção presente na referida teoria acerca da criminalidade, do crime e da pena.

\subsection{Teoria estrutural-funcionalista da anomia: fundamentos teóricos.}

Partindo do pressuposto de que o crime é um fenômeno social, Durkheim, como ressaltado no parágrafo anterior, rejeita o modelo teórico positivista-naturalista que, embora se caracterize pelo determinismo e pela preocupação etiológica também presentes na teoria estrutural-funcionalista, elege o homem delinquente como objeto de estudo. ${ }^{2}$

2 A bioantropologia positivista-naturalista enxerga nas disfunções psíquicas ou orgânicas do indivíduo as causas da criminalidade. Durkheim, contrariamente, não considera a bioantropologia criminal relevante para a explicação do fenômeno 
A tese principal de Durkheim é a seguinte: não existe grupamento social, seja ele tradicional (primitivo) ou moderno, cujos integrantes não estejam unidos entre si por vínculos de solidariedade. Segundo Durkheim, apesar das crenças morais que presidem a existência da comunidade "primitiva" terem enfraquecido com o advento da sociedade moderna esta não se encaminha necessariamente para a desintegração, mas, ao contrário, na direção da estabilidade orgânica em razão do aprofundamento da divisão do trabalho social que, recorda, também se fazia presente em menor escala na sociedade tradicional (GIDDENS, 2011, p.117-119).

Portanto, Durkheim considera que a solidariedade como fator de estabilidade social também está presente na sociedade moderna. Tanto na sociedade tradicional como na moderna os seres humanos são solidários e se identificam uns com uns outros porque compartilham valores e normas.

De acordo com Durkheim, as sociedades tradicionais reuniriam as seguintes características: diminuta população; reduzida divisão do trabalho; isolamento geográfico e social; reduzida mobilidade; homogeneidade cultural; harmonia baseada no consenso; altruísmo (espírito de corpo); importância da tradição. Em contraste, as sociedades modernas (industriais) teriam os seguintes traços: grande população; significativa divisão do trabalho; integração geográfica e

criminal enquanto fenômeno social. Figueiredo Dias e Costa Andrade têm razão quando afirmam que a concepção criminológica de Durkheim é a que "mais se distancia do modelo médico de interpretação do crime" (FIGUEIREDO DIAS; COSTA ANDRADE, 1997, p.315). 
social; intensa mobilidade social; heterogeneidade cultural; harmonia social baseada na dependência mútua e no contrato; anomia e seria orientada à mudança. ${ }^{3}$

Tanto um como outro tipo de sociedade, porém, dependem da solidariedade social para sua conservação e reprodução. Durkheim denomina "solidariedade mecânica" aquela existente na sociedade tradicional e "solidariedade orgânica" a que se faz presente na moderna.

Durkheim sustenta em $A$ divisão do trabalho social que o desenvolvimento intelectual/material da sociedade depende do aumento da força produtiva e da habilidade do trabalhador. Esta, por sua vez, decorre diretamente do grau de divisão do trabalho social que, ao final e ao cabo, resulta na solidariedade social orgânica. Consequentemente, para Durkheim, industrialização, divisão do trabalho social e solidariedade orgânica são fenômenos sociais intimamente relacionados.

Resumidamente, tem-se que tanto o desenvolvimento como a solidariedade social são consequências da divisão do trabalho social (DURKHEIM, 2008, p.30). Este fenômeno social, motor do progresso, resulta, por sua vez, em significativa medida, do

${ }^{3}$ Quando Durkheim classifica e descreve as sociedades ele vale-se de "tipos ideais". Ele esclarece aos seus leitores que "mesmo nos povos inferiores, em que a originalidade individual é pouquíssimo desenvolvida, tampouco é nula [...] uma vez que não pode haver sociedade onde os indivíduos não divirjam mais ou menos do coletivo [...]" (DURKHEIM, 2012, p.85). 
crescimento populacional. ${ }^{4}$ Com o incremento do crescimento e adensamento da população em determinado espaço territorial verificase inevitavelmente um concomitante aumento do nível de divisão do trabalho considerando-se que, segundo Durkheim (2008, p.258-259), "para que as funções se especializem mais, é necessário que haja mais cooperadores e que eles sejam bastante próximos para poderem cooperar".

Essa tese parece encerrar um paradoxo. Afinal, o aprofundamento da divisão do trabalho social não deveria produzir um grau menor e não maior de solidariedade social? Em outras palavras: o aumento do número de pessoas mais e mais especializadas no desempenho de tarefas específicas não deveria resultar em maior distanciamento entre elas e, consequentemente, no progressivo enfraquecimento da solidariedade social e não em seu aumento? A resposta de Durkheim a estas perguntas é bastante coerente.

De acordo com Durkheim, enquanto a solidariedade mecânica característica das sociedades primitivas fundamenta-se na

${ }^{4}$ Durkheim frequentemente lança mão de vocabulário extraído da biologia e desenvolve uma série de analogias entre a vida social e a vida biológica. A título de exemplo, observe-se o trecho seguinte referente à divisão do trabalho social: "Esse incremento da diferenciação social que é característico do processo de evolução das sociedades tradicionais para as formas sociais modernas pode ser comparado a certos princípios biológicos. Os primeiros organismos que nos parecem na escala evolutiva são de estrutura simples; a esses organismos seguem-se outros mais complexos, caracterizados por um grau mais elevado de especialização funcional interna: 'quanto mais especializadas as funções do organismo, mais elevada é a sua posição na escala evolutiva"” (DURKHEIM, 2008, p.119). 
tradição e na homogeneidade cultural, a solidariedade orgânica, amálgama das sociedades modernas, é produzida pela divisão do trabalho social. Assim, a solidariedade mecânica expressa a homogeneização decorrente do compartilhamento de crenças, tradições e sentimentos comuns entre as pessoas, ao passo que a solidariedade orgânica, diferentemente, reconhece a existência da diversidade de convicções e de comportamentos entre os indivíduos que a compõem. As pessoas que integram a sociedade tradicional são homogêneas; os indivíduos na sociedade moderna são heterogêneos. Por esta razão, a sociedade moderna produzida pela divisão do trabalho social cuja estabilidade é proporcionada pela solidariedade orgânica caracteriza-se pela "acentuação do individualismo" (GIDDENS, 2011, p.123).

Na sociedade moderna os indivíduos exercem profissões e ofícios muito mais especializados que os existentes nas sociedades primitivas. Nestas últimas, por exemplo, cada pessoa cuida pessoalmente dos rebanhos, das plantações, da preservação da saúde, da construção das habitações etc. Consequentemente, ao contrário do que ocorre na sociedade primitiva onde a divisão do trabalho social é bastante reduzida, na sociedade moderna caracterizada pela intensificação do processo de divisão do trabalho social, as pessoas dependem umas das outras para satisfazerem suas necessidades. $\mathrm{O}$ engenheiro não cuida dos rebanhos para garantir seu suprimento de alimento assim como o pecuarista não cuida pessoalmente de sua saúde. Toda pessoa que se dedica a uma profissão ou a um ofício depende de outra pessoa para sua sobrevivência. Em consequência, a intensificação da divisão do trabalho social gera mais e não menos 
solidariedade (DURKHEIM, 2008). Esta cooperação mútua, inclusive, não é prejudicada nem pelo individualismo nem pelo enfraquecimento da consciência coletiva característica na sociedade primitiva.

Embora a divisão do trabalho social geralmente resulte em desenvolvimento social e progresso civilizatório, excepcionalmente ela pode reduzir a solidariedade social. Este fenômeno patológico foi chamado por Durkheim de divisão anômica do trabalho.

Critica-se a tese durkheimeana da divisão do trabalho social não apenas por sua essência otimista, mas também por sua crença de que a solidariedade orgânica produz integração social e por acreditar na excepcionalidade da divisão anômica do trabalho (FIGUEIREDO DIAS; COSTA ANDRADE, 1997, p.316). Entretanto, a percepção de otimismo sobre a visão de Durkheim não é totalmente exata, afinal, quando ele debruça-se sobre o fenômeno da anomia e analisa suas causas reconhece ao mesmo tempo a possibilidade de disfunções no referido processo social cujos efeitos são socialmente desagregadores. Seja como for, excessivamente otimista ou não, o mais importante é que Durkheim contribui decisivamente para uma percepção mais consciente sobre a necessidade de superar as disfunções causadas pela divisão anômica do trabalho.

Durkheim (2008, p.367-368) afirma que a divisão anômica do trabalho tanto pode ser causada por crises industriais/comerciais como pelo antagonismo entre capital e trabalho, que ele considera a expressão mais grave do referido fenômeno. Estas disfunções produziriam um debilitamento da solidariedade orgânica em prejuízo da coesão social. 
Durkheim (2008, p.369) enxerga no industrialismo ou, mais precisamente, na contradição entre capital e trabalho a causa fundamental da divisão anômica do trabalho. Durkheim sustenta que, em parte, a tensão existente nas relações sociais resulta do fato de que "as classes operárias não querem na verdade a condição que lhes é imposta, só a aceitando, com frequência, obrigados e forçados, por não terem meios de conseguir outra”. Esta situação, por sua vez, seria causada pela alienação dos operários em relação ao trabalho decorrente da especialização excessiva que, ao invés de produzir solidariedade orgânica, resultaria em desintegração social. Durkheim (2008, p.372) afirma o seguinte acerca deste processo de alienação: "O indivíduo debruçado em sua tarefa, isola-se em sua atividade especial; ele já não sente os colaboradores que trabalham a seu lado na mesma obra, já não tem sequer a noção dessa obra comum".

Durkheim (2008, p.385-387) explica que a divisão do trabalho social quando é natural, ou seja, quando não é excessiva, não enseja a anomia uma vez que os diversos segmentos sociais mantêm um contato prolongado que desperta neles a consciência da existência de mútua necessidade de colaboração, o que, por fim, enseja a solidariedade orgânica. Todavia, diz o sociólogo francês que a situação é completamente diferente sob a égide do capitalismo industrial onde o crescimento do mercado e a aparição da grande indústria engendram mudanças radicais na relação entre patrões e operários na medida em que as máquinas substituem os trabalhadores e as manufaturas sucedem as pequenas oficinas. Além disso, no capitalismo industrial o próprio operário é afastado de sua família durante toda sua jornada de trabalho e não mantém nenhuma relação direta com seu empregador. 
Tudo isto requer regras capazes de reorganizar a vida social. Não obstante a formulação destas normas tarda por causa da rapidez com que se processam as transformações na esfera socioeconômica. Verifica-se, portanto, um descompasso entre as transformações sociais excessivamente aceleradas e a normatização do funcionamento dos organismos sociais que desequilibra os interesses antagônicos gerando conflito e impedindo a produção da solidariedade orgânica. A anomia é, em suma, produto da ausência de normatização das relações sociais. ${ }^{5}$ Durkheim (2008, p.391-398) faz distinção entre divisão espontânea do trabalho social e divisão forçada do trabalho social que produz "guerra de classes". Em seu entendimento, esta frustra as "classes inferiores" porque o ordenamento jurídico não apenas impede o exercício dos papéis que tradicionalmente foram desempenhados, mas, ao mesmo tempo, veda seu acesso às funções sociais importantes. Tais interdições produzem desigualdade de oportunidades que atingem os mais desfavorecidos. ${ }^{6}$

\subsection{Teoria estrutural-funcionalista: o direito penal e o fenômeno da criminalidade.}

${ }^{5}$ De maneira geral, no âmbito da criminologia contemporânea anomia significa basicamente ausência de leis ou de normas.

${ }^{6}$ Durkheim defende o ponto de vista de que somente as desigualdades naturais legitimam as desigualdades sociais. Embora reconheça a impossibilidade da existência de sociedades totalmente igualitárias, Durkheim sustenta que as desigualdades naturais não devem ser exacerbadas por nenhum fator de ordem externa, pois, diz ele, quando isto ocorre a "desigualdade exterior compromete a solidariedade orgânica” (DURKHEIM, 2008, p.391-398). 


\subsubsection{A criminalidade na sociedade tradicional e na sociedade moderna.}

Para Durkheim (2012, p.82), a ausência de normatização das relações sociais decorrente da divisão anômica do trabalho gera um aumento anormal das taxas de criminalidade. Ele noticia um incremento generalizado da criminalidade durante o século que teria resultado num acréscimo de quase $300 \%$ no número dos crimes cometidos na França.

Nas sociedades tradicionais, segundo sua visão, a criminalidade era baixa por causa do alto grau de consenso social decorrente de uma elevada e generalizada adesão às normas sociais. Por isso o controle social da criminalidade naquelas sociedades podia ser realizado com eficiência por instâncias informais a exemplo da família, da Igreja, da vizinhança com o objetivo de gerar solidariedade mecânica e, consequentemente, coesão social. Em contraste, nas sociedades modernas a criminalidade é mais intensa porque nelas impera a heterogeneidade decorrente da divisão do trabalho social e, em casos extremos e disfuncionais, a anomia. Nas sociedades modernas são as instâncias formais (oficiais) que protagonizam o controle das criminalidade.

Para o sociólogo francês, o direito nada mais é que um instrumento utilizado para organizar a sociedade. Ele recorda que apesar do Direito existir tanto na sociedade tradicional como na moderna, na primeira seu aspecto repressivo é mais importante, ao passo que na segunda predomina sua dimensão reparatória. No entanto, em ambas as espécies de sociedade, a reação comunitária assegura a solidariedade social mediante a punição do infrator. Por seu 
turno, o delito exprime a ruptura da solidariedade social. Não obstante, de forma aparentemente paradoxal, concorre para preservá-la ao reforçar a consciência da sociedade em torno da necessidade de preservação dos valores comuns violados pelo criminoso.

\subsubsection{As dimensões funcionais do crime e da pena na sociedade moderna.}

Durkheim admite a existência de "semelhanças essenciais" entre os crimes, mas adverte que estas não podem ser descobertas com base no exame de condutas que desde tempos remotos foram universalmente consideradas criminosas. Segundo ele, o reduzido número de comportamentos universalmente criminalizados em todas as épocas impede que, mediante generalizações, se consiga entender porque certas condutas são definidas como crimes enquanto outras não são. ${ }^{7}$ Em seu entendimento, as características das condutas criminalizadas são, em regra, muito diferentes entre si, impossibilitando a formulação de uma explicação geral satisfatória acerca da essência material dos delitos. Para ele, o crime só pode ser compreendido através do exame das condições que lhe são exteriores, razão pela qual ele elege a pena como ponto de partida de sua reflexão sobre o crime (DURKHEIM, 2008, p.39-41).

${ }^{7}$ Um tanto curiosamente, no início de sua análise sofre o fenômeno da criminalidade Durkheim emprega um conceito de crime puramente jurídico ou formal. Para ele, o crime é o comportamento que autoriza a aplicação da pena concebida como reação jurídica (DURKHEIM, 2008, p.31-39). Porém, como sociólogo Durkheim não pode deixar de se interessar pela dimensão material ou substancial dos fenômenos por ele estudados, como é o caso do crime e da pena. 
Durkheim refuta opiniões tradicionais professadas pelos juristas segundo as quais uma conduta é criminalizada porque atenta contra as "condições fundamentais da vida coletiva" ou, alternativamente, porque causa lesão aos "interesses sociais gerais". Para ele uma conduta não é criminalizada porque põe em risco à existência da sociedade. Além disso, Durkheim rechaça a ideia de que a criminalização resulta da necessidade de defesa da própria sociedade, uma das principais teses do positivismo naturalista.

Durkheim recorda que as características do Direito Penal variam de sociedade para sociedade. Tomando como base tal afirmação indiscutível, ele sustenta, contrariando o entendimento dominante, que as explicações dos juristas sobre a criminalização citadas no parágrafo anterior não devem ser aceitas por três razões: (1) primeiramente porque elas parecem supor de maneira idealizada que as reformas das legislativas consistem em reações calculadas ao crime que correm em paralelo à evolução social, ou seja, como se fossem produzidas por meio de cálculos racionais destinados a promover o ajustamento do direito repressivo às novas realidades sociais; (2) em segundo lugar, numa afirmação um tanto esquisita para um sociólogo funcionalista - porque a história revela a existência de numerosas condutas criminalizadas que não provocavam nenhuma lesão concreta à sociedade, a exemplo dos comportamentos que violavam meros tabus religiosos; (3) por último, porque em certas sociedades determinadas condutas são reprimidas penalmente enquanto outras não o são mesmo quando se revelam socialmente mais nocivas, como por exemplo uma "jogada na bolsa" ou uma falência. Em casos tais, embora as condutas descritas desorganizem o corpo social muito mais gravemente que um homicídio isolado, somente este último comportamento é definido 
como crime. Consequentemente, afirma Durkheim (2008, p.41-42), não se pode aceitar a tese de que uma ação é criminalizada por atentar contra as "condições fundamentais da vida coletiva", haja vista que "um ato pode ser desastroso para uma sociedade sem incorrer na menor repressão".

A crítica formulada por Durkheim ao entendimento tradicional acerca da natureza da criminalização é demolidora e serve de alerta a todos aqueles que pugnam na atualidade pela expansão indiscriminada do poder punitivo. Se, de fato, a criminalização independe do grau de nocividade social das condutas isto significa que a política penal precisa justificar melhor suas estratégias com base em sólidos argumentos valorativos e em dados empíricos consistentes.

Durkheim (2008, p.42) contrapõe-se igualmente à versão ligeiramente modificada da tese de que a criminalização tem lugar não exatamente porque determinadas condutas atentam contra às condições fundamentais da vida social ou violam interesses gerais, mas porque simplesmente parecem atentar contra estas condições e interesses. Para ele, esta versão alternativa não explica o porquê de tantas comunidades humanas enganarem-se com tanta frequência ao criminalizarem inutilmente condutas que nem contrariam interesses gerais e nem asseguram as condições fundamentais da vida coletiva.

Enfim, na opinião de Durkheim (2008, p.43), ressalvadas certas exceções aparentes, como no caso do incesto, "a única característica comum a todos os crimes é que eles consistem [...] em atos universalmente reprovados pelos membros de cada sociedade". E acrescenta a seguinte observação com alta dose de originalidade: a criminalização de uma conduta moralmente reprovável depende da 
intensidade dessa reprovação por parte da sociedade. Somente comportamentos internalizados pelas consciências como imorais são objeto de criminalização. Portanto, explica Durkheim (2008, p.51) que, materialmente pensado, o crime é o comportamento que "ofende os estados fortes e definidos de consciência coletiva".

Segundo Durkheim, o crime é um produto da reprovação social, porém, uma conduta não é objeto de reprovação social por ser definida como crime, mas exatamente o contrário: uma conduta é criminalizada porque é reprovada socialmente. Por sua vez, a reprovação social expressa a consciência coletiva concebida como o "conjunto de crenças e sentimentos partilhados por todos os membros da sociedade" (GIDDENS, 2011, p.121). Consequentemente, o delito não possui uma dimensão ontológica, pois o que confere caráter criminoso a um determinado comportamento "não é sua importância intrínseca, mas a que lhe é dada pela consciência comum" (DURKHEIM, 2012, p.85). Dito de outra forma: o crime é uma conduta reprovável somente na medida em que a consciência coletiva o reprova. Durkheim reconhece, dessa maneira, que o conceito de “crime natural" proposto pelo positivista Garofalo é inaceitável, haja vista que cada sociedade em particular seleciona as condutas reprováveis pela consciência comum que julga serem merecedoras de criminalização. Isto não significa que todo delito seja artificial, mas simplesmente que ele não tem conteúdo ontológico algum.

Durkheim (2008, p.62) acrescenta a observação de que não se deve supor que a sociedade reprova o crime porque seus integrantes tenham sido atingidos individualmente ao mesmo tempo pela ação delituosa, mas porque o ilícito a atinge diretamente no 
instante em que causa um dano a uma vítima em particular. Em outras palavras: para o pensador francês o crime que causa uma lesão a uma vítima individual também causa um dano direto à sociedade.

Durkheim antevê uma objeção óbvia em desfavor de seu conceito material de crime: se este é uma conduta lesiva aos estados fortes e definidos de consciência coletiva como explicar a existência de delitos que parecem não ofendê-la, a exemplo dos que se limitam a atentar contra o Estado? Como explicar, além disso, que os delitos cometidos contra o Estado costumem ser punidos mais severamente que os crimes que causam lesão exclusivamente às pessoas naturais?

Relativizando sua tese, Durkheim admite que a criminalização mais severa de ações praticadas contra o Estado não se explica - ou ao menos não se explica totalmente - por causa da intensidade da reprovação social. Diz ele, de maneira pouco convincente, que nos casos em que não há ofensa aos sentimentos coletivos, a criminalização resulta do dever que tem o poder público de "fazer respeitar as crenças, as tradições, as práticas coletivas, isto é, defender a consciência comum contra todos os inimigos de dentro como de fora" (DURKHEIM, 2008, p.54). Em sua opinião, consistindo o crime "essencialmente num ato contrário aos estados fortes e definidos de consciência comum" pode-se reconhecer a existência tanto do delito que se dirige contra indivíduos isoladamente considerados como do crime que ofende o Estado, guardião da consciência comum (DURKHEIM, 2008, p.78-80).

Por sua vez, enquanto expressão do sentimento social em relação ao crime, a pena traduz a necessidade experimentada pela sociedade de causar sofrimento à pessoa do criminoso ou, em outras 
palavras, o desejo de submeter o delinquente à expiação do delito cometido, o que, de acordo com Durkheim (2008, p.59-60), pode ser comprovado pela preocupação do legislador em graduar minuciosamente a intensidade da sanção com fundamento nas circunstâncias que tornam o crime cometido mais ou menos grave. Além disso, Durkheim também admite que a mencionada graduação se explica igualmente porque a pena é um meio de defesa. Em última análise, resume Durkheim (2008, p.61), tanto no presente como o passado a pena é um ato de vingança destinado a fazer com que o delinquente expie uma conduta que ultrajou a moral. Em seu sentir, "a natureza da pena não mudou essencialmente", mas ocorre que "a necessidade de vingança está mais bem dirigida hoje do que ontem".

Tais afirmações feitas em $A$ divisão do trabalho social que se enquadram no elenco das doutrinas tradicionais da retribuição e da prevenção distam significativamente da construção teórica mais sofisticada e complexa acerca da função da pena formulada posteriormente por Durkheim em As Regras do Método Sociológico.

Durkheim (2008, p.73) vislumbra a existência de uma dimensão funcional no delito. Em seu entendimento, "o crime aproxima as consciências honestas e as concentra". Se esta convergência não acontecesse quando do cometimento do crime, assinala, ocorreria um abalo das consciências com o passar do tempo. Consequentemente, é a comunhão social de consciências que renova os vínculos de solidariedade entre os indivíduos. Porém, para que o reforçamento dos vínculos de solidariedade tenha lugar faz-se indispensável que a sociedade reaja contra o delito, manifestando, assim, seu inconformismo diante dele e, ao mesmo tempo, reafirmando 
os valores atingidos pelo comportamento delituoso. Segundo Durkheim (2008, p.76), se a "consciência comum que é atingida, cumpre também que seja ela que resista e que, por conseguinte, a resistência seja coletiva".

Em consequência, crime e pena também apresentam uma dimensão funcional na medida em que contribuem para preservação da solidariedade orgânica indispensável à manutenção e reprodução da vida social. Mediante a aplicação da pena, acredita Durkheim, preserva-se a "fidelidade dos cidadãos médios à estrutura social", ou seja, evita-se que estes abandonem seu "comprometimento com a sociedade e sua disposição de fazer os sacrifícios necessários neste sentido" (VOLD; BERNARD; SNIPES, 2002, p.105). Esta concepção sobre a função da pena influencia o funcionalismo penal na atualidade.

Divergindo uma vez mais do positivismo naturalista, que considera o crime um fenômeno de natureza patológica e, portanto, nocivo à sociedade assim como a doença o é em relação ao corpo humano, Durkheim sustenta, contrariando mais uma vez o senso comum, que o ilícito penal não é apenas um fenômeno social normal, mas também necessário porque assegura as condições fundamentais da vida social. Em consequência, a função da pena não consiste em neutralizar o criminoso por causa de sua periculosidade, pois tanto o crime como o criminoso são, na realidade, funcionais.

Mas por que o crime é um fenômeno social normal? Durkheim (2012, p.81) responde da seguinte forma: "Um fato social é normal para um tipo social determinado, considerado numa fase determinada de seu desenvolvimento, quando ocorre na média das 
sociedades desta espécie, consideradas na fase correspondente de sua evolução". Durkheim (2012, p.82) recorda que se "não há sociedade onde não haja criminalidade" é porque a criminalidade é um fenômeno social caracterizado pela normalidade. Logo, anormal seria uma sociedade sem criminalidade. Mas Durkheim (2012, p.83) vai além e sustenta que o crime não somente é um fenômeno social normal, mas "é parte integrante de toda sociedade saudável". Por fim, Durkheim (2012, p.12) nos adverte para o fato de que a inexistência de crimes e das penas correspondentes só seria possível caso houvesse "um nivelamento das consciências individuais", o que ele reputa não apenas impossível, mas também indesejável.

Considerando que o crime (e a criminalidade) é um fenômeno social normal, Durkheim (2012, p.88) faz a seguinte advertência conclusiva: "Muito longe de ficarmos felizes quando ele desce para níveis muito abaixo do ordinário, pode-se ter certeza de que esse progresso aparente é ao mesmo tempo contemporâneo e ligado a alguma perturbação social". Uma sociedade onde as taxas de criminalidade são muito baixas atesta sua imobilidade, ou seja, sua ausência de dinamismo (VOLD; BERNARD; SNIPES, 2002, p.106).

A tese da normalidade do crime e da criminalidade colide uma vez mais com a concepção positivista naturalista e com o senso comum. Sua consequência em termos político penais mostra-se evidente: a criminalidade como um todo não pode ser eliminada, mas apenas controlada. A conhecida Lei da Saturação Criminal, formulada por Ferri, de acordo com a qual o progresso da ciência conduziria ao conhecimento integral de todas as causas da criminalidade e do peso específico de cada uma permitindo assim a adoção de medidas de 
intervenção social cientificamente fundamentadas capazes de eliminála colide diretamente com teoria estrutural-funcionalista.

A perspectiva positivista não somente é utópica, mas perigosa por favorecer o desenvolvimento de estratégias políticocriminal draconianas que sacrificam os direitos individuais em nome da promessa de eliminação total da criminalidade. Elas não apenas não têm a mínima chance de sucesso como são, em última análise, contraproducentes. O punitivismo teria consequências bastante negativas, haja vista que os direitos humanos seriam imolados no altar da utopia sem que tal sacrifício produzisse qualquer ganho, haja vista que a criminalidade continuaria a existir como sempre existiu em todas as sociedades e em todas as épocas.

Mas anormal não seria apenas uma sociedade sem criminalidade. Segundo Durkheim (2012, p.82), níveis exagerados de criminalidade possuem igualmente "natureza mórbida". Normal é simplesmente existirem delitos, posto que se a quantidade de crimes ultrapassa determinados limites, tornando-se excessiva, a criminalidade torna-se anormal.

Em suma, de acordo com Durkheim o crime é normal porque "uma sociedade totalmente isenta dele é impossível". Para que o crime não existisse numa dada sociedade seria necessário que nela os sentimentos coletivos atingidos pelo delito estivessem, sem exceção, internalizados com a mesma intensidade em todas as consciências individuais ao ponto de impedir sentimentos contrários, o que, segundo ele, é impossível de ocorrer. 
Mas Durkheim vai ainda mais longe, pois, segundo ele, a criminalidade não apenas é um fenômeno social normal, mas também necessário ou funcional.

Para o pensador francês, mesmo se hipoteticamente os sentimentos coletivos se tornassem totalmente homogêneos numa dada sociedade até a eliminação de todos os comportamentos legalmente definidos como crimes, a própria sociedade se encarregaria de criminalizar outras condutas até então penalmente indiferentes com a finalidade de proporcionar a coesão social (DURKHEIM, 2012, p.83). Em outras palavras, segundo Durkheim a existência a criminalidade e do criminoso são necessários à conservação e reprodução da vida social porque asseguram a coesão social.

Baratta (1997, p.30) considera que a teoria funcionalista de Durkheim colocou em xeque o princípio positivista "do bem e do mal" (ou "princípio da diferença") segundo o qual o criminoso é um indivíduo "anormal" em contraste com o não criminoso, que seria uma pessoa "normal". Em outras palavras, de acordo com o referido princípio os criminosos, correspondendo a uma minoria de indivíduos, são tidos como um perigo para a existência de uma sociedade sadia, ao passo que a maioria honesta da sociedade representa um bem para a vida social. O criminoso é um mal, ao passo que os cidadãos honestos são um bem. Haveria, assim, uma diferença essencial entre criminosos e não criminosos.

Baratta (1997, p.30) também afirma que, para Durkheim, ao contrário do que supõem os positivistas, as causas do crime não residem em fatores bioantropológicos e/ou naturais. Tais pontos de vista de não são incorretos, mas necessitam de uma releitura. 
Durkheim (2012, p.83) proclama a normalidade do fenômeno criminal, porém isto não significa que ele tenha chegado ao extremo de negar a diferença entre o criminoso e o não criminoso. Durkheim chega a dizer, inclusive, aproximando-se do positivismo naturalista, que "apesar do crime ser um fenômeno de sociologia normal, isto não quer dizer que o criminoso seja um indivíduo normalmente constituído do ponto de vista biológico e psicológico". Mas de modo caracteristicamente antipositivista ele sustenta, em primeiro lugar, que a anormalidade biológica e psicológica do criminoso em nada contribui para a compreensão ampla da criminalidade enquanto fenômeno social. Dito de outra forma: a bioantropologia e psicologia criminais podem nos ajudar a entender a causa de um delito isoladamente considerado como produto de anormalidades biológicas ou psicológicas de um dado indivíduo, mas não a criminalidade como um todo, tarefa da qual se incumbe a sociologia.

Por outro lado, é certo que, sob o ângulo puramente sociológico, Durkheim afirma que o criminoso desempenha uma função de grande importância na sociedade. Ao contrário do que o senso comum indica a respeito do delinquente, Durkheim (2012, p.87) sustenta que o criminoso não é de maneira alguma "um ser radicalmente insociável", mas sim "um agente regulador da vida social". Desse ponto de vista, aí sim, já não se pode considerar o criminoso como um ser antissocial, isto é, como alguém cujo comportamento delituoso afeta e, no limite, põe em risco a existência da própria sociedade. 
A normalidade e da necessidade do crime enquanto fenômeno social exige, igualmente, o reconhecimento da normalidade e da necessidade da pena, considerando-se que, de acordo com Durkheim (2012, p.12), "a instituição de um sistema repressivo não é um fato menos universal que a existência da criminalidade, nem menos indispensável à saúde coletiva".

$\mathrm{Na}$ contramão das teorias relativas da pena dominantes, Durkheim proclama que a função da pena não consiste em corrigir o criminoso (prevenção especial positiva) para evitar que este volte a cometer crimes nem em intimidar "seus possíveis imitadores" (prevenção geral negativa) para que não cometam crimes no futuro. Durkheim (2008, p.81) assinala que estes dois tipos de prevenção não são funções da pena, mas apenas efeitos secundários de sua aplicação. Em seu ponto de vista original ele sustenta que a função da pena consiste em "manter intacta a coesão social, mantendo toda vitalidade da consciência comum". Para ele, "a punição dos criminosos também atua como uma visível expressão societária da inferioridade e da culpabilidade do grupo criminoso", contribuindo para reforçar "o sentido de superioridade e de integridade encontrado na massa da sociedade e, assim, a solidariedade social" (VOLD; BERNARD; SNIPES, 2002, p.105).

Portanto, assim como o crime, a pena cumpre uma função essencial no sentido de assegurar a estabilidade social. Hipoteticamente, como assinalado anteriormente, se por algum motivo todas as infrações penais deixassem de violar a consciência coletiva e houvesse uma descriminalização total com a abolição geral de todas as figuras de ilícito penal e das penas, outras condutas 
necessariamente seriam criminalizadas e punidas, pois tanto o crime como a pena são indispensáveis à conservação e reprodução da vida social. Em suma, é impossível existir uma sociedade sem a pena, visto que a solidariedade social "é gerada pela pressão exercida pela conformidade contra a diversidade e alguma pressão será inevitável, concebida sob o formato de sanção criminal" (VOLD; BERNARD; SNIPES, 2002, p.106).

Por fim, Durkheim (2012, p.86) ousadamente vai além de tudo aquilo que afirmou sobre o crime quando argumenta que este não apenas é um fenômeno social normal e necessário, mas também é útil na medida em que contribui para a "evolução normal da moral e do direito" ao antecipar a moral futura. Durkheim (2012, p.87) recorda, por exemplo, que a prática de crime contribuiu para a expansão do ideal de liberdade. Em suas palavras:

A liberdade de pensar de que gozamos atualmente jamais poderia ter sido proclamada se as regras que a proibiam não tivessem sido violadas antes de serem solenemente revogadas. No entanto, naquele momento, essa violação era um crime, uma vez que ela era uma ofensa a sentimentos muito vivos nas generalidades das consciências. No entanto, esse crime era útil uma vez que ele preludiava transformações que, a cada dia, se tornavam mais necessárias. A filosofia livre teve por precursores as 
heresias de todo tipo que o braço secular juntamente reprimiu durante toda a idade média e até a véspera dos tempos contemporâneos.

Infelizmente, Durkheim foi bastante econômico em suas observações acerca da utilidade do crime para a evolução da moral social e do direito, limitando-se a oferecer o exemplo da condenação de Sócrates. Se historicamente certas condenações atingiram a liberdade de expressão, a liberdade de crença e as liberdades políticas e contribuíram para a formulação, consolidação e expansão dos direitos humanos uma generalização neste sentido parece impossível de ser aceita.

Sumariando a teoria funcionalista do desvio e da anomia, pode-se concluir que crime e pena são funcionais em quatro sentidos: (1) $O$ crime é funcional por contribuir para as mudanças sociais; (2) $O$ crime também é funcional por servir como alerta acerca da existência dos problemas sociais, à semelhança da função desempenhada pela dor em relação às causas últimas da doença; (3) O crime e a pena geram maior coesão social; (4) O cometimento ocasional do crime, representando uma infração de uma norma social de conduta, contribui para reforçá-la, tornando-a mais efetiva, vale dizer, a existência de um pequeno número de desviantes na sociedade revelase, afinal de contas, um benefício (MUTCHINICK; MARTIN; AUSTIN; 2009, p.36).

Registre-se, entretanto, que o funcionalismo é criticado de modo contundente sobretudo por autores marxistas e, de maneira geral, por adeptos das teorias do conflito. 


\subsubsection{A teoria estrutural-funcionalista e seus críticos.}

Critica-se o funcionalismo por comungar com os positivistas naturalistas os ideais de ordem, progresso, solidariedade e consenso social indispensáveis à ordenação da sociedade capitalista. Essencialmente anticapitalista e antiburguesa, a referida crítica formulada por Bustos Ramírez (1983, p.36) culmina na seguinte conclusão:

O funcionalismo vai se converter no século $X X$ na tentativa mais séria de estabelecer uma sociologia única e universalmente válida, o que também resulta do espírito dos positivistas, vale dizer, [de] constituir uma superciência, uma superordenação da sociedade burguesa.

Porém, a ênfase emprestada por Bustos Ramírez à "comunhão" ideológica entre o positivismo e o funcionalismo não o impede de reconhecer que o funcionalismo é superior ao positivismo porque não incorporou acriticamente a contribuição das ciências naturais ao estudo da criminalidade e, igualmente, por ter desenvolvido suas teses com base na noção de "sistema". Em suma, para ele o funcionalismo é "uma direção muito mais acabada e frutífera que o positivismo por concretizar os postulados de ordem e progresso dentro do sistema capitalista" (BUSTOS RAMÍREZ, 1983, p.38). ${ }^{8}$

${ }^{8}$ Com opinião idêntica: (SHECAIRA, 2008, p.231). 
O fato de Durkheim ter empregado a noção de estrutura social lhe permitiu conceber o fenômeno da criminalidade não como produto da liberdade da vontade, mas de comportamentos socialmente generalizados e de elementos componentes do sistema social. Desse modo, por exemplo, Durkheim tornou inteligível a tese da normalidade não apenas da criminalidade, mas de todos os demais fenômenos sociais.

Mas na opinião de Bustos Ramírez não há muita diferença entre positivismo e funcionalismo do ponto de vista gnosiológico, pois ambas as correntes defendem a tese da objetividade do conhecimento a partir da separação entre sujeito e objeto. Ademais, em seu sentir, apesar de ser uma teoria de natureza dinâmica, o funcionalismo peca por considerar o sistema como um dado inafastável, o que o torna "uma teoria do status quo", uma "ideologia de uma nascente burguesia industrial" como o positivismo, sendo que, no seu caso, uma ideologia da "burguesia industrial desenvolvida" (BUSTOS RAMÍREZ, 1983, p.38).

Shecaira (2008, p.212), na esteira de Bustos Ramírez, ressalta que o funcionalismo não se propõe a combater as disfunções sociais mediante a investigação de suas causas, mas o faz "pelo exame de suas consequências exteriores", razão pela qual considera as teorias funcionalistas como conservadoras, uma vez que "não vão às raízes do problema, que é analisado em sua superfície".

Para Shecaira (2008, p.232), o funcionalismo erra porque "parte do falso e indemonstrável pressuposto do consenso coletivo original". Em seu sentir, este pressuposto somente seria admissível tratando-se de sociedades "primitivas" que são reguladas por normas 
“espontâneas". Porém, diz ele, em sociedades complexas caracterizadas pelo pluralismo cultural não se pode admitir a ideia de consenso. Neste tipo de sociedade, o denominado consenso nada mais é que a imposição de um "critério imposto pelos grupos que detêm o poder e que simplificam assim as divergências em benefício de seus interesses". $O$ autor também recorda que, para muitos, o funcionalismo é intrinsicamente conservador por defender "a presente ordem das coisas assim como ela é, e que atacaria a conveniência de fazerem mudanças, embora moderadas" (SHECAIRA, 2008, p.233).

As observações críticas ao funcionalismo formuladas pelos penalistas citados são recorrentes na literatura penal e sociológica. Para muitos o funcionalismo descura dos conflitos sociais característicos das sociedades complexas contemporâneas. Eles lembram que as sociedades modernas, para usarmos a terminologia de Durkheim, não são nem um pouco homogêneas, muito pelo contrário. Porém, na realidade, Durkheim não disse em momento algum que as sociedades modernas são homogêneas, aliás, ele nem mesmo fez tal afirmação quando se referiu às sociedades mais simples que denominou, de acordo com o vocabulário da época, de primitivas. Não existe comunidade humana onde as crenças, as normas culturais e os valores sejam compartilhados integralmente por todos os seus membros e Durkheim sabia perfeitamente disso. Não há como negar e Durkheim não negou - que o conflito social está presente em toda e qualquer sociedade. Aliás, a conflituosidade social foi um fenômeno reconhecido por inúmeros pensadores desde a antiguidade. O próprio Marx afirma a este respeito que não foi o marxismo que percebeu pioneiramente a luta de classes. Para Durkheim se o conflito social não 
existisse todas as comunidades humanas estagnariam e não experimentariam o progresso. Em suma, a única crítica que pode ser feita à teoria estrutural-funcionalista neste aspecto reside no fato dele talvez não ter valorizado como deveria o papel fundamental que o conflito exerce nos processos de mudança social, o que não significa que tenha negado sua existência.

Por outro lado, é verdade que, ao contrário do marxismo, o funcionalismo não é uma corrente política. Durkheim não proclamou que o mundo precisa ser transformado. Mas em momento algum ele assumiu uma perspectiva normativa com a finalidade de impedir as transformações sociais, o que, diga-se de passagem, seria incoerente com a sua visão acerca do progresso. Pelo contrário, como comprova, inclusive, sua percepção da evolução das sociedades tradicionais em sociedades modernas, sua obra representa uma tentativa de compreender as mudanças então experimentadas pela sociedade francesa do seu tempo.

$\mathrm{Na}$ realidade, a crítica à teoria estrutural-funcionalista resulta da existência de duas perspectivas criminológicas distintas: as chamadas teorias do consenso relacionadas, sobretudo, ao funcionalismo, e as teorias do conflito vinculadas, especialmente, mas não necessariamente, ao marxismo. Para as primeiras há uma espécie de consenso moral na sociedade que decorre do compartilhamento de valores indispensáveis à sua estabilidade e ao equilíbrio social; para as segundas a sociedade não é um todo orgânico e homogêneo, razão pela qual não se pode falar em consenso, mas em conflito social. Em suma, para os teóricos do conflito a sociedade encontra-se cindida em 
segmentos sociais com interesses antagônicos que resultam inevitavelmente no choque entre eles (GIDDENS, 2010, p.16-17).

Porém, a dicotomia consenso/conflito é muito mais aparente que real. Ela é substancialmente artificial, pois, na realidade, consenso e conflito se encontram presentes em todas as sociedades. $\mathrm{Na}$ verdade, todas as pessoas em algum momento se movimentam na direção do consenso ou do conflito de acordo com as circunstâncias (WILLIAMS; MC SHANE, 2002, p.12).

$\mathrm{O}$ fato é que consenso e conflito não são excludentes, mas se relacionam em termos dialéticos. Se não existisse uma certa concordância social, ainda que parcial, em torno de crenças, normas culturais e valores a sociedade se desestabilizaria. Sendo assim, "certa dose de conformidade é, sem dúvida, precondição de uma sociedade estável” (CHINOY, 1976, p.625).

Por outro lado, não se pode negar que, mesmo tomando como ponto de partida a existência do consenso social em torno de crenças, normas culturais e valores, o próprio Durkheim reconheceu que o crime expressa um conflito e, de maneira mais ampla, que a anomia é consequência do conflito entre classes possuidoras e classes trabalhadoras que ocorre no curso do processo de divisão forçada do trabalho social. Na teoria estrutural-funcionalista da criminalidade há um predomínio da visão acerca do consenso social, o que não exclui o reconhecimento acerca da existência e da importância do conflito.

Críticas menos ideologicamente fundamentadas que as anteriores também são direcionadas especificamente contra a teoria estrutural-funcionalista. 
Afirma-se, com razão, que a tese de que o crime é funcional - por contribuir para as transformações sociais - não é suficientemente sólida, considerando-se que quando o delito é cometido não se pode saber com certeza se ele resultará em progresso ou não (MUTCHINICK; MARTIN; AUSTIN, 2009, p.36). De fato, somente com o passar do tempo, ou seja, com base numa visão retrospectiva, é que uma avaliação acerca da utilidade ou não do crime cometido pode ser feita - com apoio em elementos suficientes para considerá-lo ou não como socialmente positivo. A referida tese durkheimeana é, no mínimo, carente de desenvolvimento mais consistente, pois parece claro que nem todos os crimes contribuem para o progresso social.

Por outro lado, Durkheim, assim como muitos estudiosos do fenômeno da criminalidade no seu tempo, a exemplo de Ferri, se equivocou ao acreditar que os níveis de criminalidade na França estivessem aumentando anormalmente quando, na verdade, ocorria exatamente o contrário. Sabe-se atualmente que as taxas de criminalidade violenta permaneceram constantes ou mesmo regrediram em toda Europa na maior parte do século XIX. Durante a existência do sociólogo francês a criminalidade caiu ao invés de aumentar em decorrência da adoção de estratégias mais sofisticadas de controle social (MUTCHINICK; MARTIN; AUSTIN, 2009, p.43). Na França, no intervalo compreendido entre 1831 e 1931, os crimes cometidos contra o patrimônio, inclusive mediante violência, diminuíram ao invés de aumentar. De maneira mais geral, os crimes violentos não experimentaram aumento algum no referido período (VOLD; BERNARD; SNIPES, 2002, p.113). Em suma, sustenta-se 
atualmente que "aparentemente ocorreu um grande declínio nos últimos cem anos do processo de modernização, precisamente nos estágios iniciais da industrialização e urbanização, algo que a teoria de Durkheim não percebeu" (VOLD; BERNARD; SNIPES, 2002, p.115).

Com efeito, o que é bastante grave para um sociólogo, assim como ocorreu com outros criminólogos e penalistas, Durkheim provavelmente afastou-se da realidade e deixou-se levar pelo sensação de que a criminalidade estaria aumentando em ritmo acelerado na França. Em outras palavras, provavelmente atormentado, assim como outros franceses, pela sensação de insegurança característica de um mundo em transformação acelerada, Durkheim confundiu o fenômeno do crescimento real da criminalidade com o da sensação de aumento do número de crimes. ${ }^{9}$

Por fim, é indiscutível que, diferentemente daquilo que Durkheim pressupôs, a sociedade tradicional era bem menos harmoniosa, coesa e livre de crises do que ele e muitos outros imaginaram (MUTCHINICK; MARTIN; AUSTIN, 2009, p.43). Supondo que a maior coesão social era uma característica das sociedades primitivas e tornava seus membros menos propensos ao desvio, Durkheim pensou que a reação social contra as condutas desviadas seria menos violenta que as penas da modernidade. Em

${ }^{9}$ Quando Durkheim escreveu sobre a criminalidade o fenômeno da cifra oculta, de acordo o qual, por uma grande variedade de razões, os dados estatísticos oficiais acerca da quantidade de crimes cometidos em um dado território em determinado período de tempo não corresponde à realidade era então bastante conhecido. 
desafio ao senso comum bastante idealizado e ao que diziam muitos antropólogos do passado, sabe-se hoje que as sociedades "primitivas" eram muito mais violentas que as contemporâneas (VOLD; BERNARD; SNIPES, 2002, p.111).

Considerando seus pontos positivos e seus problemas, não resta dúvida que a contribuição de Durkheim ao pensamento criminológico não somente é bastante original como favorece uma percepção inteiramente nova da problemática do crime, da pena e do criminoso. Durkheim inaugura um caminho teórico completamente diferente da corrente positivista naturalista que então desfrutava de considerável influência no velho continente e, particularmente, na Itália. Para Figueiredo Dias e Costa Andrade (1997, p.314), a formulação teórica de Durkheim representa, inclusive, "o ponto de chegada da evolução da racionalidade própria das teorias etiológicoexplicativas do crime". Significa dizer que, para ambos, a teoria estrutural-funcionalista foi a teoria etiológica que mais avançou na investigação das causas da criminalidade. Em particular, Durkheim parece ter acertado ao relacionar as mutações produzidas na criminalidade contemporânea ao processo de modernização das sociedades.

Autores contemporâneos, a exemplo de Serrano Maíllo (2008, p.213-214), consideram que o conceito de anomia fornece uma explicação aceitável de como as transformações sociais abruptas dificultam a adaptação das pessoas e causam "sentimento de insegurança e falta de confiança nas normas", contribuindo, dessa maneira, para o aumento da criminalidade. Exemplificando, Serrano Maíllo cita a situação experimentada pelos soviéticos que, em um curto 
espaço de tempo, vivenciaram a transformação da estrutura socioeconômica e política da URSS. Segundo o autor, ao mesmo tempo em que foi imposta aos soviéticos uma carga mais elevada de autorresponsabilidade inexistente durante o regime socialista, a contradição representada, por um lado, pelos apelos ao consumismo e, por outro, pelo desemprego em massa, redundaram no aumento da criminalidade.

O fato é que, recorda Carbonnier (1979, p.115) acerca de Durkheim, não obstante ele tenha sido atacado inicialmente pela direita por suspeita de socialismo e, posteriormente, pela esquerda por não se posicionar politicamente, sua importância permaneceu considerável, influenciando difusamente mesmo aqueles que o criticam, mas que, ao mesmo tempo, não se furtam a empregar suas noções e ensinamentos.

Muito embora, só excepcionalmente, a doutrina penal costume reconhecer a enorme influência de Durkheim sobre as teorias penais funcionalistas, não há dúvida de que o seu pensamento encontra-se nestas presentes, como será examinado a seguir.

\section{O funcionalismo jurídico-penal: a influência da teoria estrutural-} funcionalista da criminalidade.

Tanto no Brasil como no exterior tornou-se habitual diferenciar a orientação funcionalista do Direito Penal formulada por Roxin daquela concebida por Jakobs. ${ }^{10}$ Costuma-se denominar a

${ }^{10}$ Segundo Roxin (2008, p.10), sua teoria é funcionalista porque leva em consideração à função atribuída ao injusto. Jakobs (1996, p.15), por sua vez, conceitua o funcionalismo sistêmico como sendo "a teoria segundo a qual o direito penal está 
primeira de teleológico-funcional ou moderada e a segunda de funcionalista-sistêmica ou radical. O funcionalismo teleológico não adota integralmente a metodologia funcionalista, mas o funcionalismo sistêmico nela se baseia integralmente.

Em geral, a doutrina penal nacional, ainda profundamente influenciada pelo finalismo, admite que o funcionalismo teleológico possa ser, em princípio, compatível com o Direito Penal de garantias e determinados aspectos do finalismo, mas não com o funcionalismo sistêmico. ${ }^{11}$

orientado a garantir a integridade normativa, a constituição da sociedade". Jakobs (1996, p.17) explica que "funções são as prestações que - isolada ou conjuntamente com outras - mantêm o sistema".

${ }^{11}$ Neste sentido, por todos: (BITENCOURT, 2019, p.139); (PRADO; CARVALHO; CARVALHO, 2014, p.240); (PACELLI; CALLEGARI, 2015, p.81-82). Autores eminentemente finalistas recusam, inclusive, as duas perspectivas funcionalistas. Por todos: (BRANDÃO, 2008, p.38. Na doutrina penal espanhola, Silva Sánchez (2010, p.114-115) assinala que o sistema funcionalista formulado por Roxin compõe-se de "princípios e valores político-criminais garantistas que determinam que o produto seja diferente do de Jakobs, para quem são decisivos os critérios de funcionalidade sistêmica". Por sua vez, Hassemer e Muñoz Conde (1989, p.173-174) fazem a seguinte apreciação sobre o funcionalismo penal: "Um direito penal funcionalizado pela política criminal tem mais fácil justificação utilitária de suas intervenções diante a opinião pública e pode se adaptar harmonicamente aos demais instrumentos políticos de solução dos problemas. Por isso pode-se prognosticar que a tendência à funcionalização do direito penal se manterá. Porém também deve-se assinalar contra esta tendência que o direito penal tem diante da política uma função protetora e limitadora. O perigo de uma funcionalização do direito penal é o de eliminar ou reduzir as garantias de uma elaboração formalizada do conflito porque pode perturbara os fins políticos". 


\subsection{A metodologia funcionalista $\mathrm{e}$ as teorias funcionalistas do direito penal.}

O primeiro aspecto da teoria estrutural-funcionalista de Durkheim claramente presente em ambas as teorias funcionalistas jurídico-penais é o metodológico.

Durkheim, como visto anteriormente, adota o conceito de pena como ponto de partida para o estudo do crime. Se desejamos compreender o que vem a ser o crime em sua dimensão substancial precisamos considerar seu principal efeito, vale dizer, o que vem a ser a pena. Portanto, a compreensão acerca da função da pena deve ser pressuposto de toda e qualquer investigação sobre o crime como fenômeno social.

Durkheim (2012, p.63) compreendeu a estranheza que poderia despertar esse raciocínio e explicitou sua opção metodológica nos seguintes termos:

Quando definimos o crime pela pena, nos expomos quase que inevitavelmente a acusações de querer derivar o crime da pena ou, de acordo com uma citação bem conhecida, de ver no cadafalso a origem da vergonha, não no ato expiado. Mas tal crítica é oriunda de uma confusão [...]. É verdade que a pena não faz o crime, mas é por meio dela que o crime se revela para nós em sua exterioridade, e é dela que precisamos partir se queremos compreendê-la. A objeção só seria 
fundamentada se estas características externas fossem ao mesmo tempo acidentais, ou seja, se elas não fossem relacionadas a propriedades fundamentais.

Tal posicionamento metodológico é estranho ao dogmático, considerando-se que historicamente a ciência do direito penal desenvolveu-se a partir da teoria do crime e não da teoria da pena que, aliás, sempre foi tida como uma espécie de "prima pobre" da teoria do delito, como um setor da dogmática do direito penal teoricamente atrasado. ${ }^{12}$ Com efeito, as categorias fundamentais da teoria do delito sempre foram concebidas com muita independência tanto das funções como dos fins doutrinariamente atribuídos à pena. Para os penalistas, a sanção penal sempre foi considerada mera consequência do crime que, por sua vez, é seu pressuposto incontornável. Consequentemente, os conceitos e institutos da teoria do crime não devem ser formulados com base na teoria do delito. $\mathrm{O}$ acessório deve seguir o principal e não o contrário.

Funcionalistas, porém, concebem a relação entre a teoria do crime e a teoria de pena de maneira bastante diversa. Tanto a teoria teleológico-funcional como a teoria funcionalista sistêmica, cada uma a seu modo, submetem à teoria do delito aos fins da preventivos da

12 Tornou-se célebre a afirmação de Carnelutti: "Sabemos hoje em dia muitas coisas sobre o delito, porém muito menos em torno da pena" (CARNELUTTI, 1947, p.9). 
pena. ${ }^{13}$ A teoria teleológico-funcional incorpora a inversão metodológica explicitamente e considera que pena e medida de segurança são "o ponto de referência comum a todos os preceitos jurídico-penais, o que significa que o direito penal em sentido formal é definido por suas sanções" de maneira que "se um preceito pertence ao direito penal não é porque regule normativamente a infração de mandatos ou proibições [...] mas porque essa infração é sancionada mediante penas ou medidas de segurança" (ROXIN, 1997, p.41).

Esta reorientação metodológica de natureza caracteristicamente funcionalista cuja origem se encontra em Durkheim tem consequências importantes para o sistema de direito penal denominado racional-final, teleológico ou funcional por Roxin.

Explicitando a metodologia por ele adotada, Roxin (1997, p.203) contrapõe-se ao finalismo por entender que o sistema jurídicopenal "não pode vincular-se a realidades ontológicas prévias" a exemplo das estruturas lógico-objetivas, mas deve conduzir-se de acordo com os fins que lhes são atribuídos. Isto considerado, Roxin propõe "substituir a um tanto vaga orientação neokantiana baseada nos valores culturais por um critério de sistematização especificamente jurídico-penal: as bases político-criminais da moderna teoria dos fins da pena”.

${ }^{13}$ Referindo-se a inovação metodológica funcionalista no campo do direito penal, Serrano Maíllo (1999, p.157) diz que "o ponto de partida de tal dogmática penal não é outro que uma concepção preventiva da pena, constituindo essa a autêntica finalidade reconhecida à sanção penal". 


\subsection{A função da pena na teoria estrutural funcionalista e o funcionalismo penal.}

Contudo, a influência de Durkheim sobre o funcionalismo penal também se faz presente na doutrina da pena. Durkheim, como visto anteriormente, afirmava que a função da pena consistiria em contribuir para a coesão social ao reforçar a consciência comum em torno dos sentimentos ofendidos pelo delito. Consequentemente, a função da pena consistiria em assegurar a fidelidade das pessoas à estrutura social. As finalidades costumeiramente atribuídas à pena seriam não sua função, mas meros efeitos secundários. Em suma: Durkheim (2012, p.19) diz explicitamente que a função da pena consiste em "manter intacta a coesão social, mantendo toda a vitalidade da consciência comum". Portanto, qualquer utilidade advinda da aplicação da pena seria um efeito puramente secundário e não sua função.

Sem chegar ao extremo de imaginar a função da pena nos termos concebidos pela teoria estrutural-funcionalista, Roxin não a despreza, muito pelo contrário. Embora proponha o que denomina de "teoria unificadora preventiva", que contempla quase todos os fins preventivos comumente atribuídos à pena pela doutrina penal e os vincula especificamente as três fases (legislativa, judicial e executória) da criminalização, tal autor confere especial destaque à denominada teoria da prevenção geral positiva cuja origem se encontra na estrutural-funcionalista. ${ }^{14}$

${ }^{14}$ Sobre a teoria unificadora preventiva: (ROXIN, 1997, p.95 e ss). 
Mesmo concedendo que a prevenção geral positiva não seria suficiente para concretizar a missão do direito penal que, quando da publicação da primeira edição de seu tratado, consistiria exclusivamente na proteção subsidiária de bens jurídicos, Roxin (1997, p.91) afirma que o aspecto positivo da pena preventiva expressa-se exatamente "na conservação e no reforço da confiança na firmeza e poder de execução do ordenamento jurídico" que, esclarece em seguida, não se confunde com seu "efeito intimidatório".

No funcionalismo sistêmico a influência da teoria estrutural-funcionalista da pena é ainda mais pronunciada que na teoria teológico-funcional. Mesmo admitindo-se que a doutrina da prevenção geral positiva de Jakobs é formada a partir de múltiplas fontes provenientes tanto do direito como da filosofia e da sociologia, não se pode desconsiderar que a herança durkheimeana encontra-se presente quando, ao tratar do significado da pena, ele afirma que a pena não previne a lesão a bens jurídicos, mas tem por missão "reafirmar a vigência da norma" permitindo, desse modo, que ela "siga sendo um modelo idôneo de orientação" (JAKOBS, 1997, p.13-14).

Consoante esta concepção acerca da finalidade da sanção penal, a pena se desdobraria em três subfinalidades estreitamente relacionadas: (1) a pena reafirmaria a confiança na norma por parte da sociedade e, ao mesmo tempo, faria com que o infrator se apercebesse dos custos que lhe acarreta; (2) a pena exercitaria a fidelidade ao direito; (3) a pena exercitaria o cidadão na aceitação das consequências da violação da norma (JAKOBS, 1997, p.16). 
Na esteira do pensamento de Durkheim, Jakobs (1997, p.19) esclarece a respeito dos fins preventivos gerais negativos da pena:

Secundariamente, a pena pode impressionar de tal modo aquele que a sofre ou a terceiros para que estes se abstenham de realizar fatos futuros. Estes efeitos produzidos, não só por reconhecimento da norma, mas por medo, são algo que cabe desejar que se dê por acréscimo na pena, porém não é função da pena provocar tais efeitos.

Em outras palavras, assim como Durkheim, Jakobs defende a tese de que a função da pena não consiste em intimidar, em coagir psicologicamente a generalidade das pessoas para que não cometam crimes no futuro, mas em exercitar a prevenção geral positiva "não para dissuadi-los mediante a intimidação, mas como valor simbólico, produtor de consenso", bem como para "reforçar a confiança no sistema social em geral e no sistema penal em particular" (ZAFFARONI; ALAGIA; SLOKAR, 2000, p.60).

Há, entretanto, uma diferença essencial no âmbito epistemológico entre a teoria estrutural-funcionalista e as teorias funcionalistas penais no que diz respeito à pena. Enquanto cientista social, Durkheim preocupa-se em descrever e explicar a realidade do fenômeno da criminalidade, do crime e da pena. Ele se propõe a descrever, explicar e compreender o referido fenômeno sociojurídico tomando a realidade tal como ela é. Seu esforço de compreensão, 
portanto, se situa no mundo do ser e não do dever ser. Os autores do funcionalismo, pelo contrário, não obstante a influência exercida pelo pensamento de Durkheim sobre suas próprias doutrinas, não tratam do problema da pena a partir de uma postura sociológica, vale dizer, não estão propriamente interessados em averiguar no que consiste a função da pena, mas assumem uma perspectiva caracteristicamente filosóficojurídica consistente em preocupar-se com o fim ou os fins que a pena deve perseguir. Neste sentido, Jakobs (em menor medida) e Roxin (mais nitidamente), movem-se no mundo do dever ser. Suas teorias da pena possuem conteúdos nitidamente prescritivos. Ferrajoli (2002, p.264), por sinal, após afirmar que a teoria da prevenção geral positiva de Jakobs nada acrescentou à teoria durkheimeana, reconhece que Durkheim "não teve a intenção de dar uma justificação, mas apenas uma explicação acerca da pena".

Na realidade, mesmo autores agnósticos em relação à pena admitem de modo expresso que "em boa medida as teorias sobre a prevenção geral positiva descrevem dados que correspondem ao que acontece na realidade", embora acrescentem em seu desfavor que "seu defeito mais evidente é ético, porque legitimam o que acontece, pelo mero fato de que o consideram positivo para que nada mude, chamando sistema ao status quo e lhe concedendo valor supremo" (ZAFFARONI; ALAGIA; SLOKAR, 2000, p.61).

Fato é que, na atualidade, segmentos importantes da doutrina penal nacional e estrangeira adotam mesmo que parcialmente a visão de que a pena também tem por missão a prevenção geral positiva em alguma de suas formas. Hassemer (1999, p.111), para citar apenas um penalista bastante conhecido no país, afirma, por exemplo, 
que as normas sobrevivem não somente quando se pune pública e energicamente sua violação, mas também quando elas são preservadas de qualquer tipo de negação. E esclarece expressamente que esta é a sua concepção preventiva geral positiva da pena. Em resumo, a despeito das críticas direcionadas às teorias funcionalistas jurídicopenais da pena, a ideia de que a prevenção geral positiva, sobretudo quando associada a outras finalidades, deve ser perseguida pelo direito penal, parece viver atualmente seu melhor momento entre os penalistas desde que foi elaborada no âmbito do direito penal.

Conclusão: a influência de Durkheim sobre as teorias funcionalistas penais.

A importância de Durkheim demorou a ser reconhecida internacionalmente. Somente na década de 30 do século passado é que os países de língua inglesa perceberam a originalidade de sua obra. A partir de então, o funcionalismo tornou-se bastante influente no mundo acadêmico, intervindo na visão de gerações de sociólogos. Porém, apesar disso sua importância demorou a ser sentida na seara penal. Somente nas derradeiras décadas do século anterior é que a teoria estrutural-funcionalista da anomia faz-se presente ainda que indiretamente na dogmática do Direito Penal, mais especificamente na teoria funcional-teleológica e na teoria funcionalista-sistêmica, esta última manifestamente dependente das formulações de Luhmann, sociólogo alemão.

Esta reflexão demonstrou a influência durkheimeana sobre dois aspectos das teorias funcionalistas penais: (1) a metodologia empregada na formulação dos sistemas de Direito Penal, que elege como ponto de partida o conceito de pena permitindo que as categorias fundamentais da teoria do crime derivem da teoria da pena; (2) a teoria 
da prevenção geral positiva que integra a teoria preventiva mista (unitária) de Roxin e esgota por completo a concepção preventiva da pena formulada por Jakobs.

Evidentemente este estudo sucinto está distante de esgotar o exame de todas as questões tratadas no texto as quais certamente merecerão uma atenção mais ampla e aprofundada em investigações ulteriores. No entanto, esta reflexão sobre a importância do pensamento de Durkheim para o Direito Penal abre espaço para uma compreensão mais exata de algumas dimensões relevantes do funcionalismo penal, orientação doutrinária que aparentemente caminha para tornar-se - se já não se tornou - hegemônica entre os penalistas brasileiros.

\section{REFERENNCIAS}

BARATTA, A. Criminologia crítica e crítica do direito penal: introdução à sociologia do direito penal. Trad. Juarez Cirino dos Santos. Rio de Janeiro: Revan, 1997.

BITENCOURT, C. R. Tratado de direito penal: parte geral. 25.ed. São Paulo: Saraiva, 2019, v.1.

BRANDÃO, C. Curso de direito penal: parte geral. Rio de Janeiro: GEN/Forense, 2008.

BUSTOS RAMÍREZ, J. Criminología y evolución de las ideas sociales. In R. Bergalli, J. Bustos Ramírez, T. Miralles (orgs.). El pensamiento criminológico: un análisis crítico. Bogotá: Temis, 1983, p.27-48.

CARBONNIER, J. Sociologia jurídica. Trad. Diogo Leite de Campos. Coimbra: Almedina, 1979.

CARNELUTTI, F. El problema de la pena. Buenos Aires: Ediciones Jurídica Europa-América, 1947. 
CHINOY, E. Sociedade: uma introdução à sociologia. Trad. Octávio Mendes Cajado. São Paulo: Cultrix, 1976.

DURKHEIM, E. Da divisão do trabalho social. 3.ed. Trad. Eduardo Brandão. São Paulo: Martins Fontes, 2008.

DURKHEIM, E. As regras do método sociológico. Trad. Walter Sólon. São Paulo: EDIPRO, 2012.

FERRAJOLI, L. Teoria del garantismo penale. 7.ed. Roma: Laterza, 2002.

FIGUEIREDO DIAS, J. de; COSTA ANDRADE, M. da. Criminologia: o homem delinquente e a sociedade criminógena. Coimbra: Coimbra Editora, 1997.

GIDDENS, A. Sociologia. 8.ed. Trad. Alexandre Figueiredo et alii. Lisboa: Fundação Calouste Gulbekian, 2010.

GIDDENS, A. Capitalismo e moderna teoria social. 7.ed. Trad. Maria do Carmo Cury. Lisboa: Presença, 2011.

HASSEMER, W.; MUÑOZ CONDE, F. Introducción à la criminología e al derecho penal. Valencia: Tirant lo Blanch, 1989.

HASSEMER, W. Persona, mundo y responsabilidad. Bogotá: Temis, 1999.

JAKOBS, G. Sociedad, norma y persona en una teoría del delito funcional. Madrid: Civitas, 1996.

JAKOBS, G. Derecho penal: parte general. Fundamentos y teoría de la imputación. 2.ed. Madrid: Marcial Pons, 1997.

MUTCHNICK, R. J.; MARTIN, R.; AUSTIN, T. W. Criminological thought: pioneers past and present. Columbus: Prentice Hall, 2009. PACCELI, E.; CALLEGARI, A. Manual de direito penal. São Paulo: Atlas, 2015. 
PRADO, L. R.; CARVALHO, E. M. de; CARVALHO, G. M. de. Curso de direito penal brasileiro. 13.ed. São Paulo: Revista dos Tribunais, 2014.

ROXIN, C. Derecho penal: parte general. Fundamentos. La estructura de la teoría del delito. Madrid: Civitas, 1997, t.1.

ROXIN, C. Evolución y modernas tendencias de la teoría del delito en Alemania. México: UBIJUS, 2008.

SERRANO MAÍLLO, A. Ensayo sobre el derecho penal como ciencia: acerca de su construcción. Madrid: Dykinson, 1999.

SERRANO MAÍLLO, A. Introdução à criminologia. Trad. Luiz Régis Prado. São Paulo: Revista dos Tribunais, 2008.

SHECAIRA, S. S. Criminologia. 2.ed. São Paulo: Revista dos Tribunais, 2008.

SILVA SÁNCHEZ, J. M. Aproximación al derecho penal contemporáneo. 2.ed. Montevideo: B de F, 2010.

VOLD, G. B.; BERNARD, T. J.; SNIPES, J. B. Theoretical criminology. 5.ed. New York, Oxford: Oxford University Press, 2002.

WILLIAMS, F. P.; McSHANE, M. D. Devianza e criminalità. Trad. Vicenzo Scalia. Milano: Il Mulino, 2002.

ZAFFARONI, E. R.; ALAGIA, A.; SLOKAR, A. Derecho penal: parte general. 2.ed. Buenos Aires: EDIAR, 2000. 